Sharif University of Technology
Scientia Iranica
SCIENTIA
I RAN ICA
http://scientiairanica.sharif.edu

Research Note

\title{
Experimental evaluation of effective parameters on characteristic curves of hydraulic ram pumps
}

\author{
R. Fatahi-Alkouhi and B. Lashkar-Ara* \\ Department of Civil Engineering, Jundi-Shapur University of Technology, Dezful, Iran.
}

Received 26 November 2016; received in revised form 6 June 2017; accepted 13 November 2017

\section{KEYWORDS}

Ram pump;

Dimensional analysis;

Characteristic curves;

Non-linear regression;

Impulse valve.

\begin{abstract}
The effects of non-dimensional parameters on the characteristic curves of a ram pump were evaluated in this study using an experimental model. To do so, after providing dependent and independent parameters using dimensional analysis, effect of each independent parameter was examined on the dependent parameter. Experimental observations showed that relative pumping discharge $\left(q / Q_{T}\right)$, relative wasting discharge $\left(Q / Q_{T}\right)$, and pump efficiency $(\eta)$ depended on length to diameter ratio of drive pipe $(L / D)$ and pressure head ratio $\left(h / h_{m}\right)$. Impulse valve parameter $\left(n D / \nu_{0}\right)$ depended on $L / D$, $h / h_{m}$, and Reynolds number of flow in drive pipe. Characteristic curves were presented for the ram pump used in this study to estimate dependent parameters as functions of pressure head for various ratios of length to diameter. In addition, characteristic equations of the used ram pump were introduced using nonlinear regression. Evaluation of results showed that the characteristic curves and equations could design a ram pump system with high accuracy, and this design method could be used for any kind of ram pumps with engineering purposes.
\end{abstract}

(C) 2019 Sharif University of Technology. All rights reserved.

\section{Introduction}

Water supply to remote sites is often performed with pump driving energy. Some limiting factors such as access road and energy sources have led to limitations on pump choices. On sites that stream with a considerable gradient is available, water can be piped down a grade to power a hydraulic ram pump that will lift water to the higher location in 24 hours a day. A Hydraulic Ram Pump is a feasible solution to the geographic and economic conditions that do not have an external energy source, such as electricity or fossil fuels. This system can pump water to the rural and tribal areas where the construction of water transfer

\footnotetext{
*. Corresponding author.

E-mail address: Lashkarara@jsu.ac.ir (B. Lashkar-Ara)
}

doi: $10.24200 /$ sci. 2017.4597 systems cannot be justified economically. The ram pump, by using water hammer energy and management of its own energy received from the water supply head, makes it possible to pump the water to a considerable height after a periodic operating cycle.

\subsection{The working cycle of hydraulic ram pump} The cycle of ram pump is divided into three phases: acceleration, pumping, and recoil. At the start of acceleration phase, the flow in the drive pipe is at rest. Impulse valve is open and the delivery valve is closed. The flow accelerates under the action of the supply head until the dynamic force exerted on the impulse valve by the flow is sufficient to cause the valve to begin closing. Flow velocity in drive pipe continues to increase and the impulse valve starts to close at a certain critical velocity. At the end of acceleration phase, the impulse valve is closed rapidly and water hammer phenomenon occurs. Now, pumping takes 


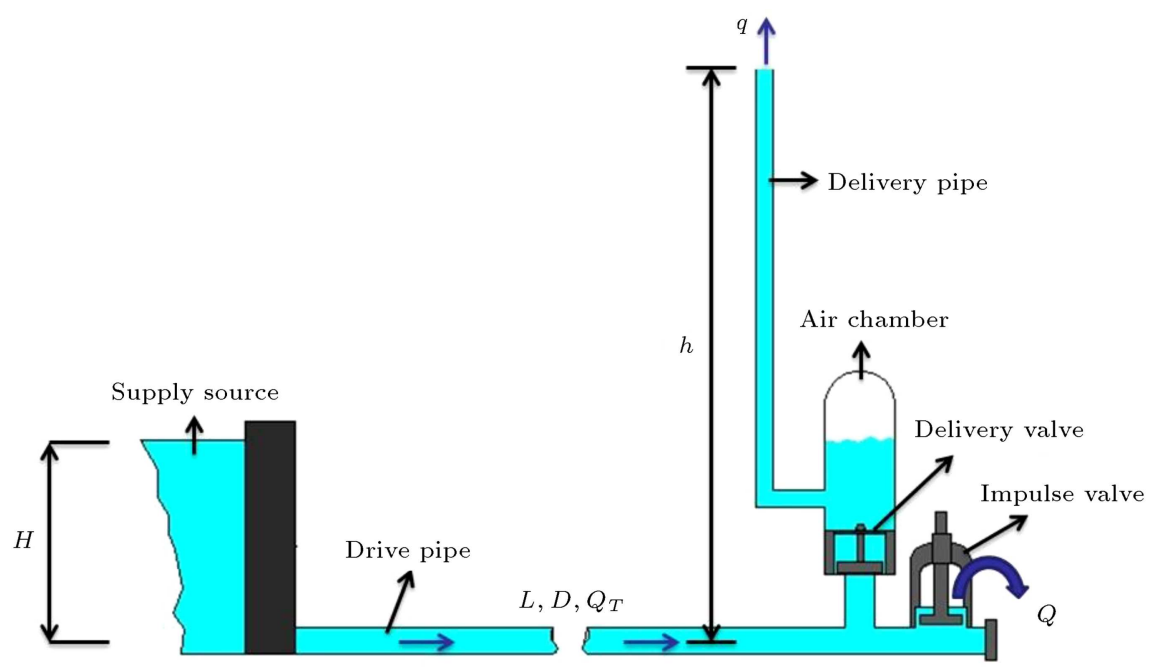

Figure 1. Layout of hydraulic ram pump system.

place as shock waves induced by water hammer pass up and down the drive pipe at the pressure wave velocity; the delivery valve is open in response to each pressure pulse and flow is pumped toward the storage tank. Recoil, the reversal of flow in the drive pipe, occurs at the end of the pumping phase after the delivery valve is closed. The suction resulting from the recoil causes the impulse valve to open and makes the cycle ready to begin again. Components of a ram pump system are shown in Figure 1.

\subsection{Review of previous studies}

The ram pump was invented by Whitehurst in 1797 to supply water to a brewery factory. After the invention of the hydraulic ram pump, there were unsuccessful attempts to provide a rational theory to explain the ram pump performance until the early twentieth century [1]. The first rational theoretical analysis of the ram pump behavior was presented by O'Brien and Gosline [2]. They assumed four time zones in the ram pump cycle. In [2], pumping phase occurred when the impulse valve was closed, and the propagation of pressure waves occurred in the drive pipe after water hammer. Krol [3] assumed seven phases in the ram pump cycle and presented a complex analysis of it. Rennie and Bunt [4] investigated the operation of the hydraulic ram pump. They studied various impulse valves and drive pipe diameters experimentally. Schiller and Kahangire [5], by using numerical methods, concluded that the exact theories for predicting the performance of ram pumps were complex. They assumed four phases in ram pump cycle and ignored the effect of pressure waves during acceleration due to their complexity. In their model, an increase or a decrease in speed during acceleration and the duration of impulse valve closure were linear. The output of their model included the delivered quantity, pump efficiency, and cycle time. They concluded that a general empirical formula could not compare the different designs. Basfeld and Müller [6] presented a simplified theory by developing Newton's equations of motion and taking into account loss factors and boundary conditions. The results from their theory were compared with the measurements of Plexiglas' model of a hydraulic ram pump. In particular, the time dependence of the flow velocity in the drive pipe, the water volume delivered per work cycle, and the efficiency were experimentally determined as the functions of various parameters. Tacke [7] carried out some experiments on 12 commercial ram pumps and explained their behavior using a modified version of [2]; the velocity diagram was divided into three time zones in their study. Rennie and Bunt [8] presented a graphical approach in order to design ram pumps by using analytical model and experimental validation. Young [9] presented two simple equations to design the ram pump $(H=B q h, n L=A q h)$. These equations contained some empirical factors, which were dependent upon ram size, delivery head, material, wall thickness of the drive pipe, and the configuration of the impulse valve. Young [10] studied Wilcox's ram pump and presented a simplified analysis under ideal condition (recoil equal to zero) for ram pump action. Under this condition, Eqs. (1) to (4) were offered to design the ram pump. These equations can be used for designing ram pumps with the sizes of 19 to $102 \mathrm{~mm}$.

$$
\begin{aligned}
& n L D^{2}=20 q h, \\
& H D^{2}=4.6 q h, \\
& Q_{T}=0.7 D^{2}, \\
& L_{\max }=110 H D .
\end{aligned}
$$

Young [11] introduced the optimum design range for non-dimensional parameters determined analytically 
under ideal condition by using experimental results of previous researchers. Najm et al. [12] developed a numerical model for the analysis of water hammer pressure waves in the ram pump and examined the impact of the waves on the ram pump components. Maratos [13] investigated the relationship between quantities delivered and drive pipe diameter, and evaluated the change of velocity in time cycle on the velocity-time diagram. Filipan and Virag [1] presented a mathematical model using the method of characteristics. In this study, the mathematical modeling of particular components such as drive and delivery pipes, supply and storage tanks, and set of ram pump was explained in detail. Then, by using boundary conditions, 11 equations with 11 dependent variables were solved by an iterative procedure for each time step of the computational run. The outputs of the model were presented in the form of pressure and velocity versus time graphs. Suarda and Wirawan [14] examined the effect of air chamber on the ram pump performance. They showed that the efficiency of the ram pump without air chamber was about 1 percent and the efficiency of the ram pump with air chamber was about 20 percent. Saito et al. [15] evaluated the effects of the air volume in air chamber on the hydrodynamic characteristics and operating conditions of ram pumps. Evaluations showed that the peak pressures in the valve and air chambers varied depending on the pump head and the peak pressure in the valve chamber, and the peak pressure in the air chamber tended to decrease as the air volume in the air chamber increased. Nwosu and Madueme [16] a constructed hydraulic ram pump, which was used to increase the head of the falling water. The rates of flow of water from the tank and pumping water into the tank were designed to operate in an optimum manner. A controlled actuator was used in order to maintain the flow rates. The underground tank was made to store rain water and it was capable of meeting the water need of the micro hydropower plant in the off-rain periods. Sheikh et al. [17] studied the literature available and prepared a structured design methodology for hydraulic ram pump (HYDRAM), which covered design parameters, design procedure, and the mathematical relationship applied in the design procedure. Yang et al. [18], by using experimental evaluation, showed that adding a short cambered diffuser between the elbow and the impulse valve in the ram pump increased the ram pump efficiency to 53 percent. Inthachot et al. [19] added an off-the-shelf clap check valve to the ram pump, which led to increase in the efficiency of pump by over 30 percent. The results of the field observations showed that this ram pump supplied the irrigation of lands for the Northern area of Thailand with efficiency of 44 percent in the range of six weeks. Mbiu et al. [20] presented the design development of a durable and locally made hydram using inexpensive and readily available materials. A test rig was fabricated and used to analyze the different parameters of the hydram. Optimizing these parameters ensured that the hydram performance was enhanced and, as a result, gave the pump a longer life. Experimental and analytical modelling results were generalized in performance charts and compared with commercially available types of operating characteristics. These results would enable the targeted users to select appropriate sizes for their water pumping needs.

\subsection{Objectives of study}

Reviewing the previous studies about hydraulic ram pumps showed that simultaneous evaluation of all effective parameters on the ram pump performance was not performed. Therefore, the aim of this study is to evaluate the performance of ram pump using the selective effective parameters. To accomplish the objective of this study, several experiments were performed. First, all effective dimensional parameters on ram pump performance were identified. Then, numerous experiments were performed to evaluate the performance of ram pump based on each of the identified effective parameters. The performance results were used to develop characteristic curves that could be used in practical application of ram pump.

\section{Materials and methods}

\subsection{Experimental setup}

Experimental results were used to evaluate effective parameters on ram pump characteristic curves. Thus, by developing an experimental model consisting of a ram pump set (51 $\mathrm{mm}$ in diameter) and auxiliary equipment, such as pressure control board of delivery head and pressure control board of supply head, the performance of the ram pump system was evaluated in the research laboratory of Hydraulic and River Engineering Department at Jundi-Shapur University of Technology. Figure 2 shows a schematic of the experimental model used in this study.

In order to perform experiments using laboratory model, the flow was connected to the system. Then, by opening the control valve of the supply control board, the supply head was adjusted. By adjusting the control board of delivery head in the desired height, the tests were performed. By automatic opening and closing of the impulse valve, and the occurrence of intermittent cycles, a part of input discharge was pumped and the excess of it was removed from the system through impulse valve as wastewater. Then, the quantities of pumping and wasting discharge and frequency of impulse valve were recorded during each test. The duration of each test was set to 20 minutes. In each scenario, the pump performance was evaluated for 


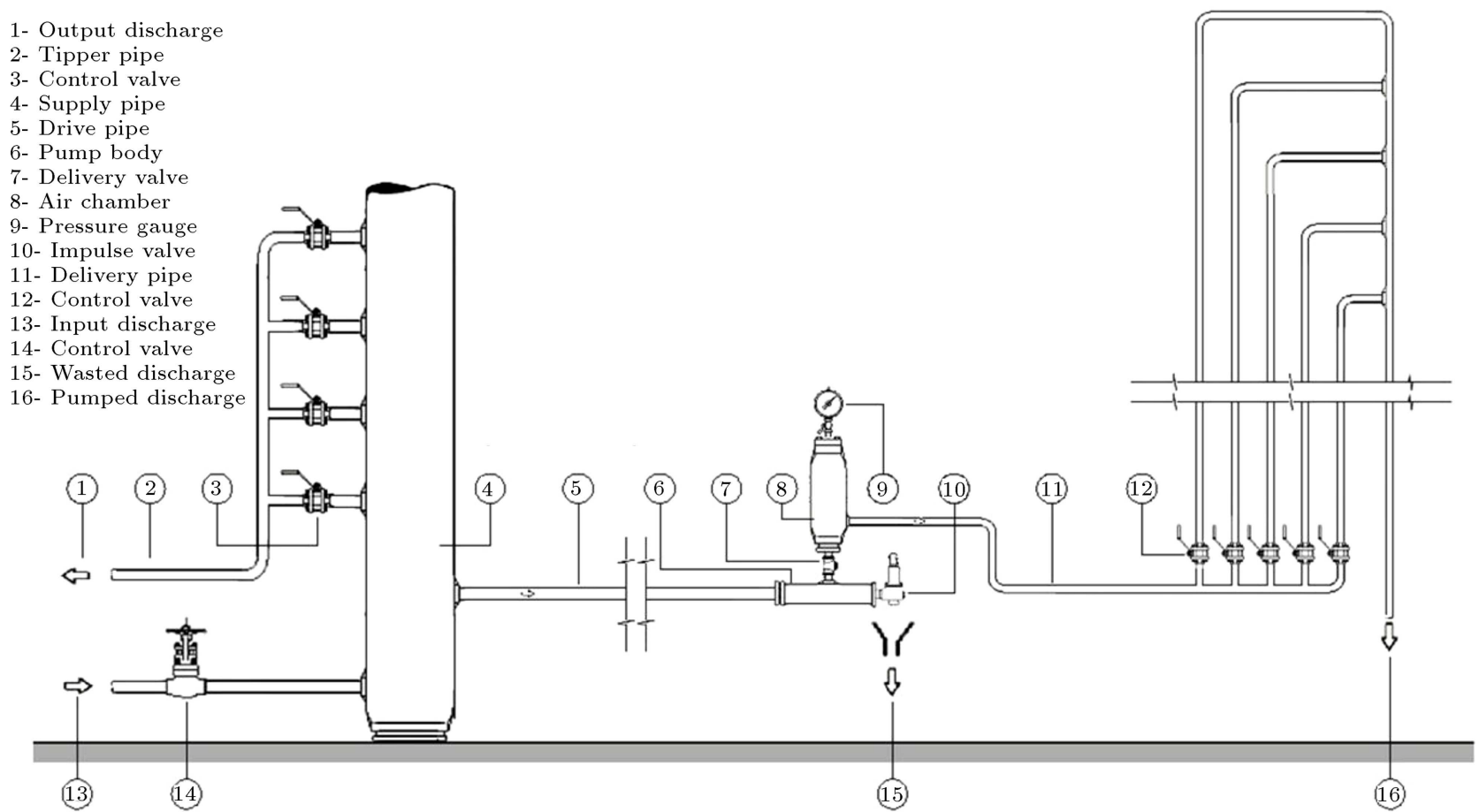

Figure 2. Schematic of experimental setup.

Table 1. Conditions of length to diameter ratios of drive pipe in this study.

\begin{tabular}{cccc}
\hline $\begin{array}{c}\text { Number of } \\
\text { scenarios }\end{array}$ & $\begin{array}{c}\text { Length of Diameter of } \\
\text { drive pipe } \\
\boldsymbol{L}(\mathbf{m})\end{array}$ & $\begin{array}{c}\text { Length to } \\
\text { drive pipe } \\
\boldsymbol{D}(\mathbf{m})\end{array}$ & $\begin{array}{c}\text { diameter ratio } \\
\boldsymbol{L} / \boldsymbol{D}\end{array}$ \\
\hline S1 & 5.10 & 0.05 & 100 \\
S2 & 10.20 & 0.05 & 200 \\
S3 & 15.30 & 0.05 & 300 \\
S4 & 10.20 & 0.02 & 400 \\
S5 & 12.75 & 0.02 & 500 \\
S6 & 15.30 & 0.02 & 600 \\
\hline
\end{tabular}

delivery heads of 2,3 , and 4 meters versus supply heads of 1 and 1.5 meters. Similarly, the performance of the pump was investigated in delivery heads of 3 and 4 meters versus supply heads of 2 and 2.5 meters. Table 1 shows the governing scenarios in this study.

\subsection{Dimensional analysis}

After recording laboratory values, the analysis of the results was carried out. Hence, applying a dimensional analysis and the $\pi$-Buckingham theory, the effective parameters on the ram pump performance were determined. According to Figure 1 and with regards to hydraulic flow in this category of pumps, the dependent and independent parameters of the pumping system of the ram pump were listed as the following.

The delivery head or pumping head $(h)$; supply head of water source system $(H)$; characteristics of drive pipe including pipe modules of elasticity $(E)$, pipe diameter $(D)$, and length of pipe $(L)$; characteristics of fluid including density $(\rho)$, bulk modules $(k)$, and dynamic viscosity of fluid $(\mu)$; acceleration due to gravity $(g)$; density of the constituent materials of the impulse valve $\left(\rho_{m}\right)$; friction coefficient of fluid and internal pipe wall $(f)$; the total input discharge $\left(Q_{T}\right)$; and maximum pumping head or delivery head $\left(h_{m}\right)$ were the independent parameters of the hydraulic ram pump system. On the other hand, the variables such as pumping discharge $(q)$, wasting discharge $(Q)$, frequency of impulse valve $(n)$, the velocity of pressure wave $(C)$, the critical velocity required to close the impulse valve $\left(\nu_{0}\right)$, and pump efficiency $(\eta)$ constituted the dependent variables. It was assumed that the modulus of elasticity and bulk modulus only influenced the pressure wave velocity, and the density of the constituent of impulse valve only influenced the critical velocity required to close impulse valve. On the other hand, the kinematics viscosity of the fluid $(v)$ was used instead of the values of dynamic viscosity $(\mu)$ and fluid density $(\rho)$ in order to reduce the independent variables. Thus, the independent variables were limited to 11 variables including $\left(Q_{T}, h_{m}, h, H, D, L, f, v, g, C, \nu_{0}\right)$ and the dependent variables were limited to $(q, Q, n, \eta)$. Finally, the dimensional analysis was conducted based on the dependent and independent variables of the hydraulic ram pump system, and the relationship between independent parameters was indicated as the following: 


$$
\begin{aligned}
& \frac{q}{Q_{T}}=\phi_{1}\left(\frac{\nu_{0} D}{v}, \frac{\sqrt{g H}}{\nu_{0}}, \frac{\nu_{0}}{C}, \frac{h}{h_{m}}, \frac{L}{D}, f\right), \\
& \frac{Q}{Q_{T}}=\phi_{2}\left(\frac{\nu_{0} D}{v}, \frac{\sqrt{g H}}{\nu_{0}}, \frac{\nu_{0}}{C}, \frac{h}{h_{m}}, \frac{L}{D}, f\right), \\
& \frac{n D}{\nu_{0}}=\phi_{3}\left(\frac{\nu_{0} D}{v}, \frac{\sqrt{g H}}{\nu_{0}}, \frac{\nu_{0}}{C}, \frac{h}{h_{m}}, \frac{L}{D}, f\right), \\
& \eta=\phi_{4}\left(\frac{\nu_{0} D}{v}, \frac{\sqrt{g H}}{\nu_{0}}, \frac{\nu_{0}}{C}, \frac{h}{h_{m}}, \frac{L}{D}, f\right),
\end{aligned}
$$

where, the relative parameter $\nu_{0} D / v$ indicates Reynolds number, the relative parameter $\sqrt{2 g H} / \nu_{0}$ indicates Froude number, and the relative parameter $\nu_{0} / C$ indicates the Mach number. On the other hand, $q / Q_{T}$ is relative pumping discharge, $Q / Q_{T}$ is relative wasting discharge, $n D / \nu_{0}$ is impulse valve parameter, $\eta$ is pump efficiency, $h / h_{m}$ is pressure head ratio, $L / D$ is length to diameter ratio of drive pipe, and $f$ is friction coefficient.

\subsection{Methodology}

To present characteristic curves of ram pump, hydraulic features of pumping system such as maximum delivery head and loss values of impulse valve were determined. Losses in the impulse valve could be divided into two parts:

1. Loss due to the drag coefficient, which was determined using the rule of drag force [3];

2. Loss due to the friction coefficient of impulse valve, measured by water manometer using the slop difference of energy line between the sides of the impulse valve at different lengths of stroke valve.

Therefore, attempts were made to provide the empirical equations and graphs to determine the loss coefficients of impulse valve. To measure maximum delivery head of ram pump, after closing the control valve that was installed on the delivery pipe, under various laboratory conditions, maximum delivery head regardless of the loss values in delivery pipe was measured by using pressure gauge. Based on the relationship between dependent and independent parameters in Eqs. (5) to (8), by performing experimental evaluation, the effect of independent parameters on the ram pump performance was taken into account. By evaluating the ram pump performance versus the effective parameters on its performance, characteristic curves of ram pump were presented. Characteristic equations governing the research were presented to estimate the relative pumping discharge, relative wasting discharge, parameter of impulse valve, and pump efficiency. The SPSS software was used in order to detect the nonlinear relationship between the dependent and independent parameters of the dimensional analysis. After the dimensional analysis and the determination of the general form of characteristic equations in this study, it was necessary to change the process of the independent parameters and their effect on the dependent parameters evaluated. To do this, it was necessary to do a statistical analysis. The error functions used in the present study to evaluate the results of the proposed equations included the Mean Percentage Error (MPE), Root Mean Square Error (RMSE), correlation coefficient $\left(R^{2}\right)$, Standard Error Estimates (SEE), and modeling efficiency (EF). The gradient of regression line $(m)$ between results and experimental observations was calculated for evaluating the performance of the equations in a way that their intercept elevations became zero. It is worth noting that if the value of $m$ is close to one, the predicted results are close to the experimental observations.

\section{Results}

After recording the experimental observations and evaluating ram pump performance versus Reynolds number, Froude number, Mach number, pressure head ratio, length to diameter ratio of drive pipe, and friction coefficient of fluid and pipe, effective parameters were selected. To do so, independent parameters were changed under identical laboratory condition; then, the changes of dependent parameters were measured. Experimental observations showed that the changes in Reynolds number had not effect on the quantities of relative pumping, wasting discharge, and pump efficiency. However, the changes in the Reynolds number had an effect on the impulse valve parameter. On the other hand, the changes in parameters of Froude number, Mach number, and friction coefficient had not effects on the ram pump performance and could be neglected. Out of other independent parameters of dimensional analysis, the pressure head ratio and length to diameter ratio of drive pipe were notable. The experimental evaluation of these parameters indicated that the changes in ratios of length to diameter of drive pipe and to pressure head had significant effects on the ram pump performance. Thus, the effects of these parameters could not be ignored. Table 2 shows the ranges of experimental observations of dependent and effective independent parameters.

As mentioned in the section on material and methods, the loss of impulse valve was divided into two parts including the loss caused by friction coefficient and the loss of the drag coefficient. Results of loss values measured for an impulse valve with disc diameter of $35 \mathrm{~mm}$ and weight of $135 \mathrm{gr}$ are provided in Table 3 .

In order to facilitate the exploitation of the results presented in Table 3, two empirical equations based on the experimental observations are presented in the form of Eq. (9) and (10) to determine friction coefficient and drag coefficient. Note that these relations correspond 
Table 2. The ranges of experimental data used in the present study.

\begin{tabular}{cccccc}
\hline No. & $\begin{array}{c}\text { Dimensionless } \\
\text { parameter }\end{array}$ & Maximum & Minimum & Average & $\begin{array}{c}\text { Standard } \\
\text { deviation }\end{array}$ \\
\hline 1 & $q / Q_{T}$ & 0.34 & 0.008 & 0.16 & 0.09 \\
2 & $Q / Q_{T}$ & 0.99 & 0.65 & 0.83 & 0.09 \\
3 & $n D / \nu_{0}$ & 0.27 & 0.01 & 0.09 & 0.07 \\
4 & $L / D$ & 600 & 100 & 364.91 & 166.35 \\
5 & $h / h_{m}$ & 0.86 & 0.2 & 0.48 & 0.18 \\
7 & $\nu_{0} D / \nu$ & 29568 & 12724 & 20877 & 7547 \\
\hline
\end{tabular}

Table 3. Experimental values of impulse valve loss in various valve strokes.

\begin{tabular}{ccccc}
\hline $\begin{array}{c}\text { Valve strokes } \\
\boldsymbol{S}_{\mathbf{0}}(\mathbf{m m})\end{array}$ & $\begin{array}{c}\text { Velocity of } \\
\text { valve closure } \\
\boldsymbol{\nu}_{\mathbf{0}}(\mathbf{m} / \mathbf{s e c})\end{array}$ & $\begin{array}{c}\text { Ratio of } \\
\boldsymbol{S}_{\mathbf{0}} / \boldsymbol{D}_{\boldsymbol{\nu}} \\
\text { (dimensionless) }\end{array}$ & $\begin{array}{c}\text { Drag } \\
\text { coefficient }\end{array}$ & $\begin{array}{c}\text { Friction } \\
\boldsymbol{K}_{\boldsymbol{d}}\end{array}$ \\
\hline 1.5 & 0.24 & 0.04 & 25.01 & $\boldsymbol{c}$ \\
3.2 & 0.47 & 0.09 & 6.17 & 58.85 \\
4.7 & 0.75 & 0.13 & 2.48 & 19.93 \\
6.4 & 1.01 & 0.18 & 1.36 & 8.67 \\
8 & 1.24 & 0.22 & 0.90 & 6.71 \\
9.5 & 1.44 & 0.27 & 0.66 & 5.42 \\
11.1 & 1.64 & 0.31 & 0.52 & 4.49 \\
12.7 & 1.83 & 0.36 & 0.41 & 3.80 \\
\hline
\end{tabular}

to the specifications of impulse valve used in the ram pump of this study.

$$
\begin{aligned}
& K_{d}=0.0453 \times\left(\frac{S_{0}}{D_{v}}\right)^{-2.0381}, \\
& R^{2}=0.99, \quad R M S E=0.08, \\
& c=0.7312 \times\left(\frac{S_{0}}{D_{v}}\right)^{-1.4141}, \\
& R^{2}=0.99, \quad R M S E=0.83 .
\end{aligned}
$$

Out of the other features of the ram pump used in this study, it is necessary to point the maximum delivery head up. In general, every pump can pump water to a certain height depending on the specifications of the ram pump system. The observations showed that the parameters such as supply head $(H)$ or its effect on flow velocity in steady state $\left(\nu=(2 g H)^{0.5}\right)$, length to diameter ratio $(L / D)$, and the critical velocity to close impulse valve $\left(\nu_{0}\right)$ had a significant effect on the maximum delivery head. By evaluating the ratio of $h_{m} / H$ versus independent parameters of $\nu / \nu_{0}$ and $L / D$, a diagram is presented in Figure 3 to determine the maximum delivery head.

Using the statistical functions, an equation is presented to determine the maximum delivery head for the ram pump designed in this study. The mapping

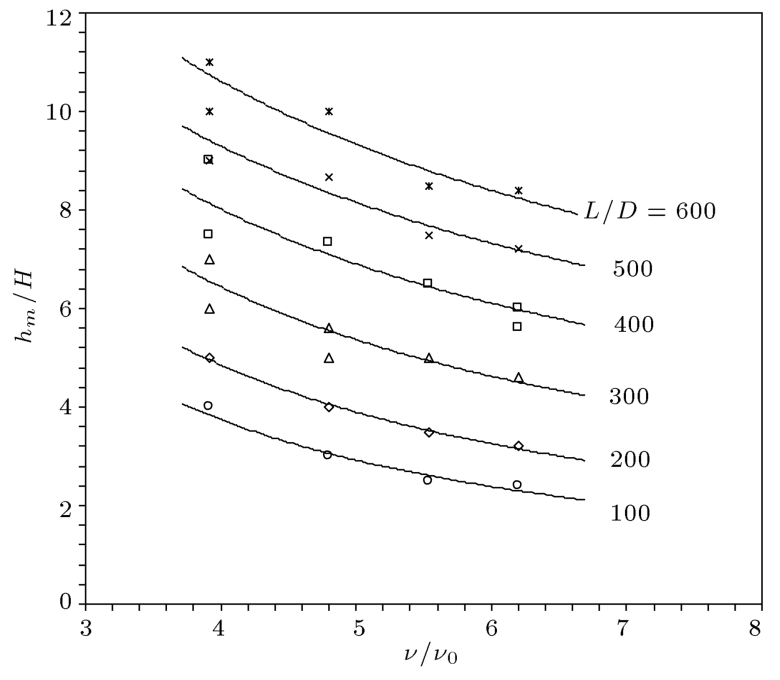

Figure 3. Determination head ratio of $h_{m} / H$ versus velocity ratio of $\nu / \nu_{0}$ for different ratios of $L / D$.

between the independent parameters $L / D$ and $\nu_{0} / \nu$ and dependent parameter $h_{m} / H$ is presented in Relation (11):

$$
\begin{aligned}
& \frac{h_{m}}{H}=0.247 \times\left(\frac{L}{D}\right)^{0.729} \times\left(\frac{\nu}{\nu_{0}}\right)^{-0.644}, \\
& R^{2}=0.97 \quad R M S E=0.53,
\end{aligned}
$$

where $\nu_{0}$ is the required velocity to close the impulse valve and $\nu$ is flow velocity in a steady state. To 
determine the critical velocity required for closing the impulse valve, Eq. (12) is provided based on the law of drag force [3]:

$$
\nu_{0}=\sqrt{\frac{W g}{K_{d} \rho A_{\nu}}},
$$

where, $W$ is weight of impulse valve, $\rho$ is fluid density, and $A_{\nu}$ is disc area of impulse valve. The aim of this study is to present the characteristic curves of the utilized ram pump. To do so, attempts were made to provide the necessary conditions for estimating the quantities of pumping discharge, wasting discharges, impulse valve parameter, and pump efficiency under different conditions. Thus, all experimental observations of the dependent parameters were evaluated versus the pressure head ratio for different ratios of length to diameter of drive pipe. Figures 4 to 7 show the ram pump characteristic curves to determine the relative pumping discharge, relative wasting discharge, impulse valve parameter, and pump efficiency.

In order to facilitate the use of results in Figures 4 to 7 , characteristic equations are presented. According to the evaluation of the effects of independent parameters on the ram pump performance, it was found that relative pumping discharge, relative wasting discharge, and pump efficiency were dependent on changes of length to diameter ratio of drive pipe and pressure head ratio. On the other hand, impulse valve parameter was dependent on Reynolds number and ratios of pressure head and length to diameter of drive pipe. The mappings of the proposed equations between the dependent and independent parameters were provided as the following:

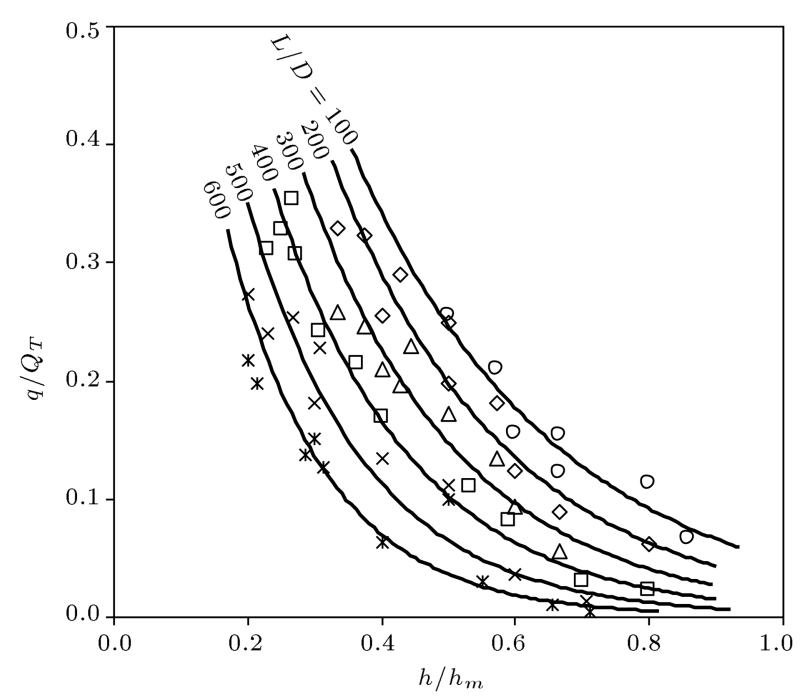

Figure 4. Characteristic curve to determine the values of $q / Q_{T}$ versus $h / h_{m}$ for different ratios of $L / D$.

$$
\begin{aligned}
& \frac{q}{Q_{T}}=\frac{0.1525 \times\left(\frac{L}{D}\right)^{-0.3971}}{0.0498+\left(\frac{h}{h_{m}}\right)^{4.2051}}, \\
& \frac{Q}{Q_{T}}=0.56\left(\frac{L}{D}\right)^{0.1039}\left(\frac{h}{h_{m}}\right)^{0.2561}, \\
& \frac{n D}{\nu_{0}}=0.000096 \times\left(\frac{L}{D}\right)^{-0.679} \times\left(\frac{h}{h_{m}}\right)^{0.33} \times \operatorname{Re}^{1.087} \\
& \eta=-0.2688+\left(\frac{L}{D}\right)^{-0.0479}-0.4763\left(\frac{h}{h_{m}}\right)^{1.2507}
\end{aligned}
$$

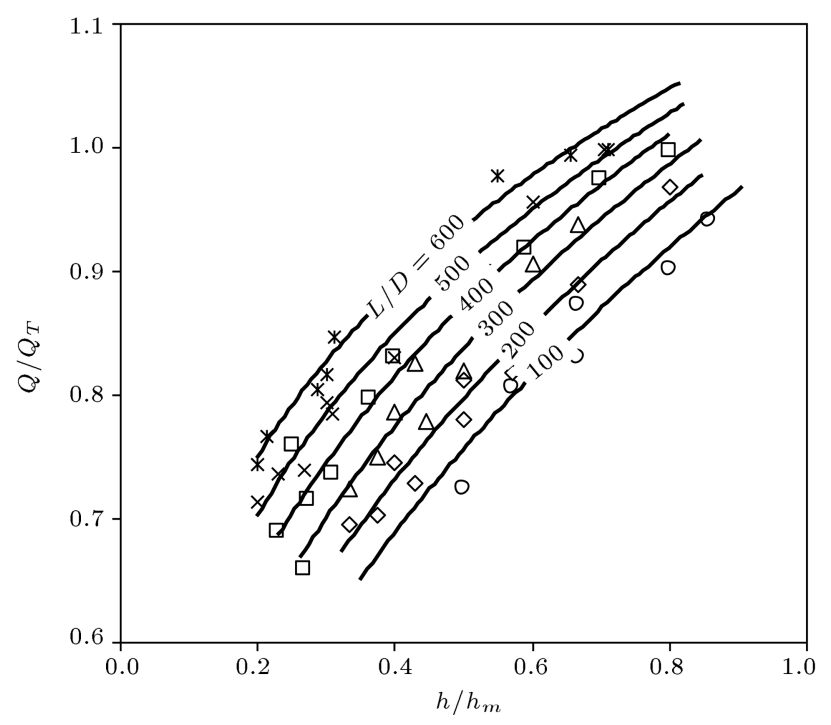

Figure 5. Characteristic curve to determine the values of $q / Q_{T}$ versus $h / h_{m}$ for different ratios of $L / D$.

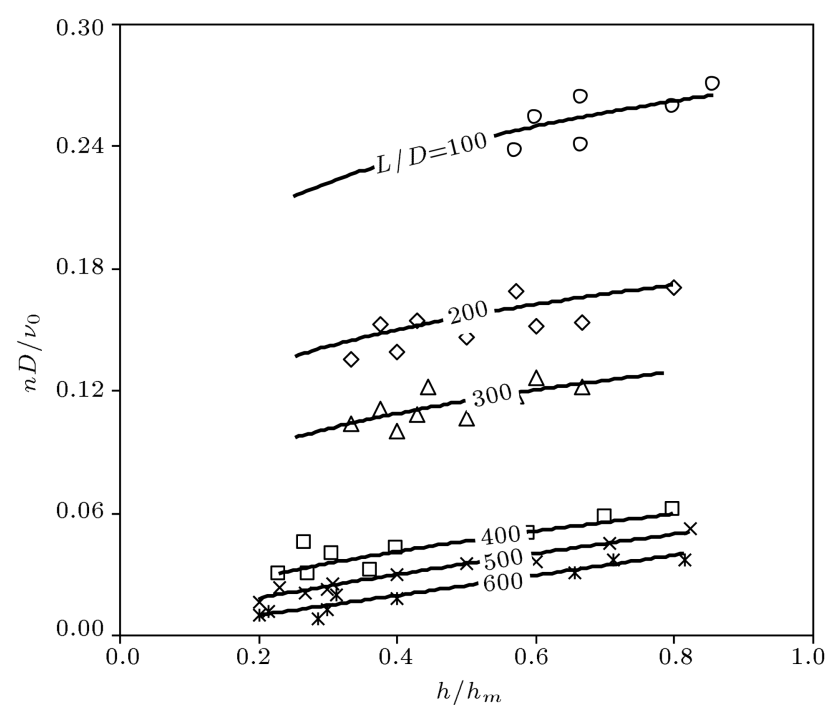

Figure 6. Characteristic curve to determine the values of $n D / \nu_{0}$ versus $h / h_{m}$ for different ratios of $L / D$. 


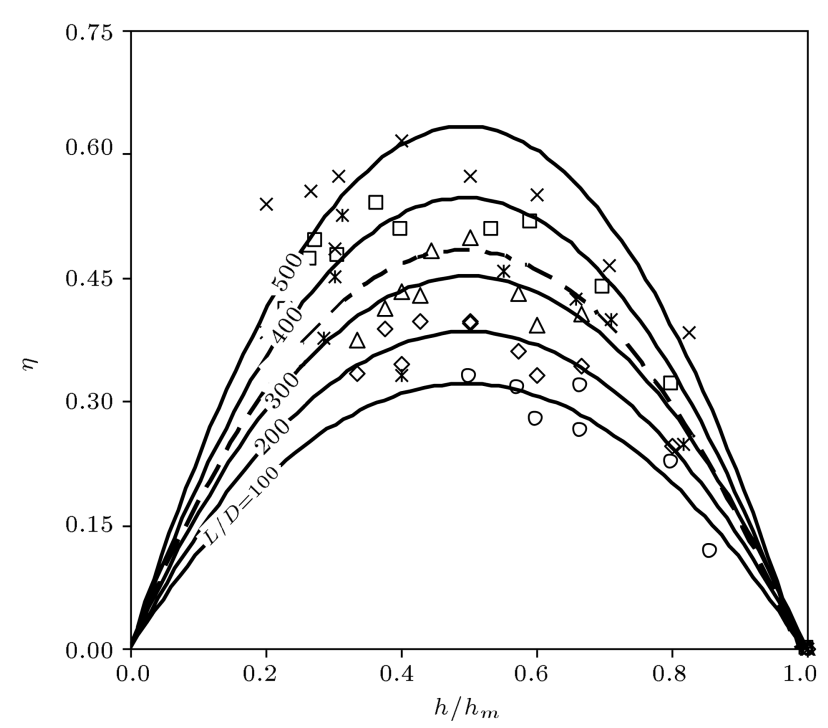

Figure 7. Characteristic curve to determine the values of $\eta$ versus $h / h_{m}$ for different ratios of $L / D$.

\section{Discussion}

As mentioned in the subsection on methodology, the error functions were used to evaluate the results of study. Statistical analysis was performed on Eqs. (13) to (16) and the results of error functions based on the prediction parameters $q / Q_{T}, Q / Q_{T}, n D / \nu_{0}$, and $\eta$ are briefly provided in Table 4 .

Statistical analysis of error functions based on the prediction of experimental values by the produced equations showed that Eq. (13) predicted the relative pumping values by root mean square error of 0.0338 . Also, the evaluation of the gradient of regression line between the calculated results and experimental observations showed that this equation predicted relative pumping discharge 2.26 percent lower than the experimental observation. On the other hand, the proposed equations had root mean square errors of 0.0405 and 0.0105 in estimating the relative wasting discharge and impulse valve parameters, respectively. The evaluation of the gradient of regression line between calculated results and experimental observations showed that Eq. (14) predicted the relative wasting discharge 0.24 percent lower than the experimental observations. Also, Eq. (15) predicted the impulse valve parameter 0.76 percent lower than the experimental observations. Eq. (16) had an RMSE of 0.0357 in the prediction of the ram pump efficiency. Therefore,

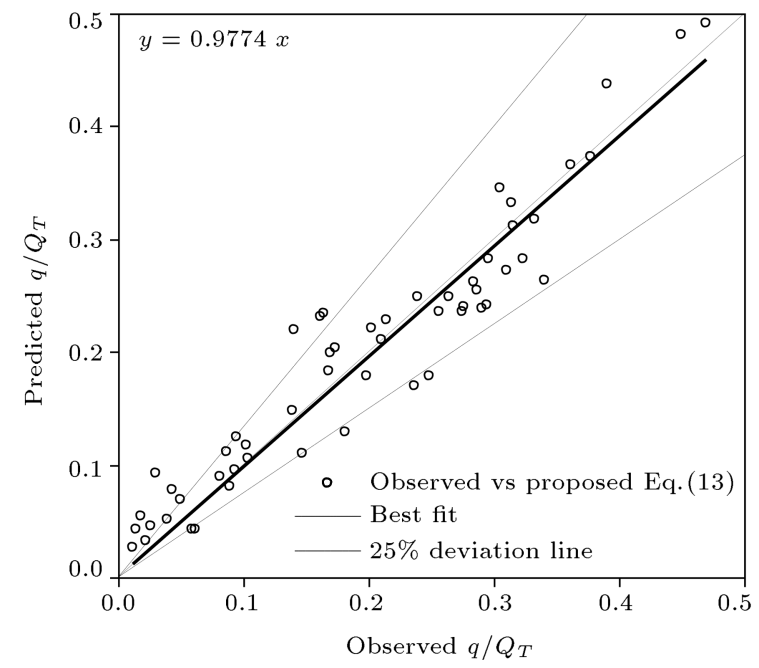

Figure 8. The predicted values of $q / Q_{T}$ by Eq. (13) versus experimental observations.

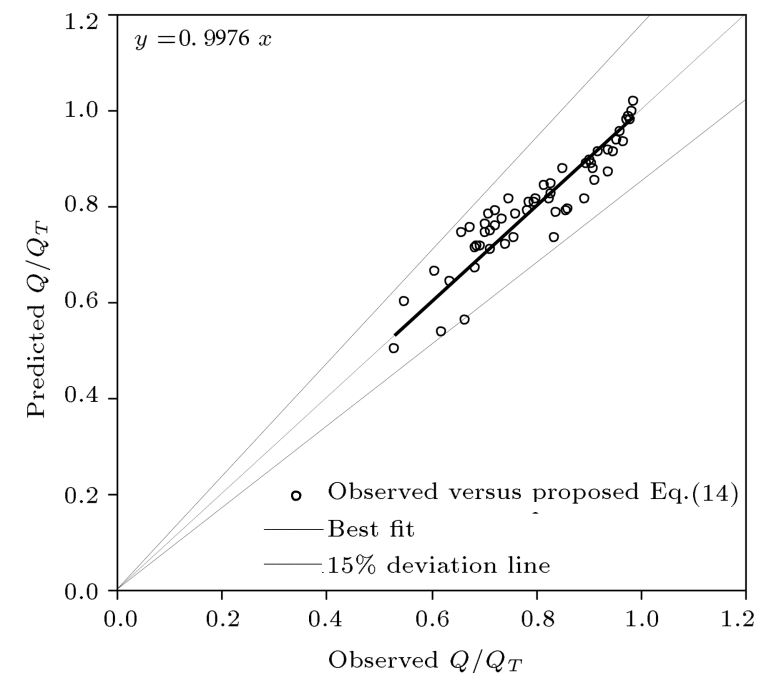

Figure 9. The predicted values of $Q / Q_{T}$ by Eq. (14) versus experimental observations.

this equation predicted it 1.55 percent lower than the experimental observations. The other error functions in Table 4 show that the proposed equations, called characteristic equations, could be used to design the ram pump with height accuracy. Figures 8 to 11 show the gradients of regression line based on the predicted values by the proposed equations versus experimental observations, and the correlation coefficient of these equations.

Table 4. The brief results of error functions based on the proposed equations.

\begin{tabular}{ccccccc}
\hline Parameter & Equation & RMSE & MPE & SEE & EF & $\boldsymbol{m}$ \\
\hline$q / Q_{T}$ & $(13)$ & 0.03 & 1.83 & 0.03 & 0.91 & 0.97 \\
$Q / Q_{T}$ & $(14)$ & 0.04 & 0.22 & 0.03 & 0.88 & 0.99 \\
$n D / \nu_{0}$ & $(15)$ & 0.01 & 1.29 & 0.01 & 0.98 & 0.99 \\
$\eta$ & $(16)$ & 0.03 & 1.83 & 0.03 & 0.88 & 0.98 \\
\hline
\end{tabular}




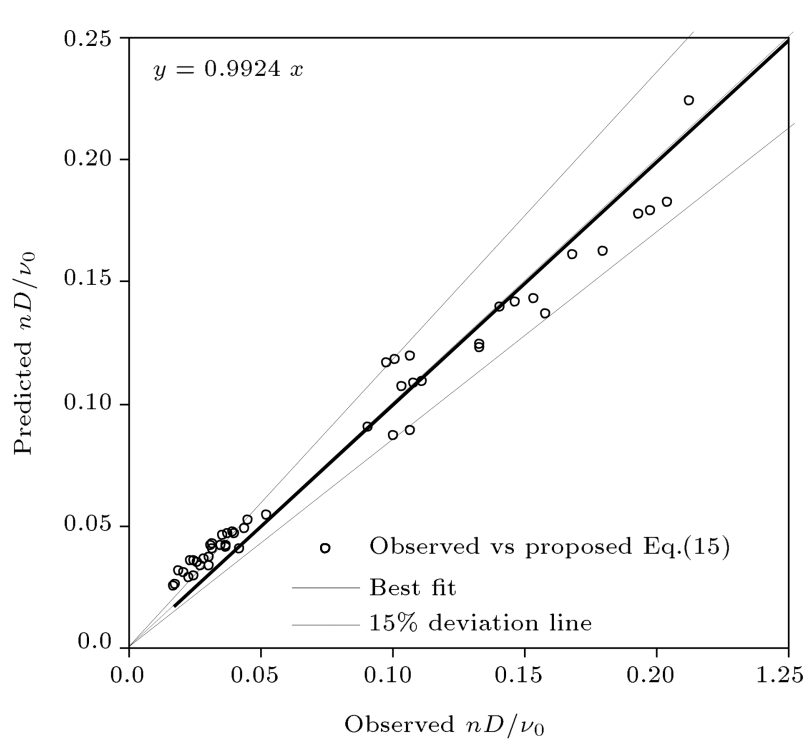

Figure 10. The predicted values of $n D / \nu_{0}$ by Eq. (15) versus experimental observations.

In order to design a pumping system using the results in this study, first, length of drive pipe was determined according to the topographical conditions of water supply and installation position of pump device. In addition, its diameter was selected by taking into account the discharge capacity of supply source and economic conditions. As well, pressure head ratio was estimated after calculating maximum delivery head (Eq. 11) and measuring delivery head. In practice, total input discharge $\left(Q_{T}\right)$ is dependent on capacity of water supply source and it is determined using hydrometric methods or other empirical methods. Finally, pumping discharge, wasting discharge, frequency of impulse valve, and pump efficiency could be determined using Figures 4 to 7 or Eqs. (13) to (16), respectively.

Experimental results showed that by increasing length of drive pipe, pumping discharge increased, and wasting discharge and frequency of impulse valve decreased. On the other hand, increasing length to diameter ratio of drive pipe led to increase in pump efficiency and, according Figure 7 , after $L / D=500$,

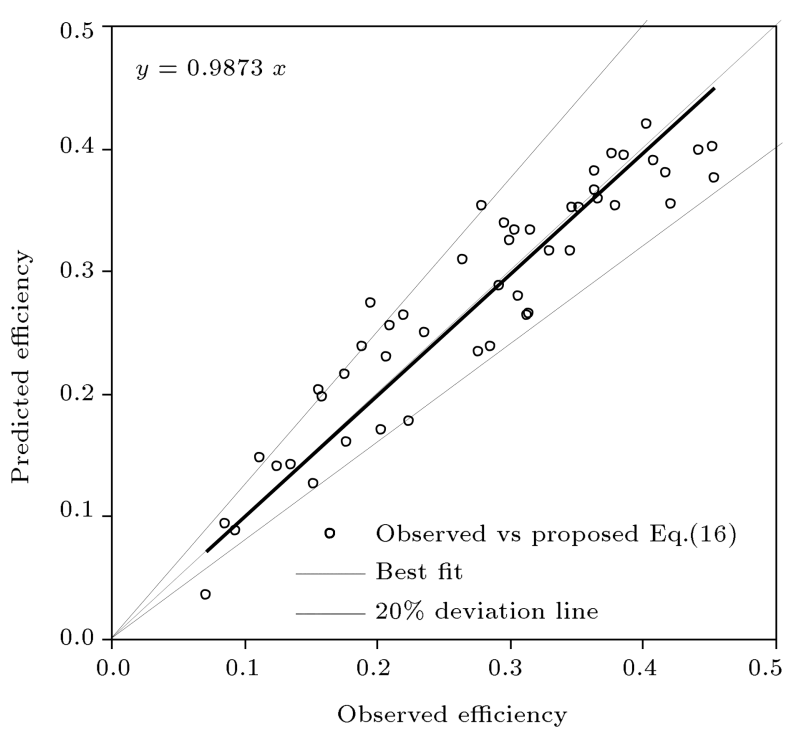

Figure 11. The predicted values of $\eta$ by Eq. (16) versus experimental observations.

pump efficiency decreased. Reduction in pump efficiency means that it is better to increase the size of the ram pump.

A practical example is presented to explain how to use the proposed method for designing a ram pump system. In this example, source capacity $\left(Q_{T}\right)$ of pumping system is $27 \mathrm{l} / \mathrm{m}$, and supply head and delivery head are 2.5 and $15 \mathrm{~m}$, respectively. In order to evaluate performance of the ram pump used in this study, first, a pumping system including Wilcox ram pump was designed using Young's method (Eqs. (1) to (4)). The brief results of the designed system are shown in Table 5 .

In a similar condition, the ram pump used in the present study was designed using the proposed method. To evaluate the ram pump used in this study, an attempt was made to consider some features of the ram pump system designed in Table 5, such as length and diameter of drive pipe. Therefore, independent variables and features of the ram pump used in this study were selected and brief results are shown in

Table 5. Steps of designing a pumping system using Wilcox's ram and Young's method.

\begin{tabular}{ccccc}
\hline Step & $\begin{array}{c}\text { Parameter } \\
\text { design }\end{array}$ & $\begin{array}{c}\text { Equation } \\
\text { number }\end{array}$ & $\begin{array}{c}\text { Parameter } \\
\text { value }\end{array}$ & Dimension \\
\hline 1 & $D$ & Eq. $(3)$ & 0.02 & $\mathrm{~m}$ \\
2 & $L$ & Eq. $(4)$ & 7.01 & $\mathrm{~m}$ \\
3 & $q$ & Eq. $(2)$ & 1.41 & Liter $/ \mathrm{min}$ \\
4 & $Q$ & $Q=Q_{T}-q$ & 25.59 & Liter $/ \mathrm{min}$ \\
5 & $n$ & Eq. $(1)$ & 1.55 & $\mathrm{~min}^{-1}$ \\
6 & Number of cycles per min & - & 93 & ${\text { Beat } / \mathrm{min}^{-}}^{2}$
\end{tabular}


Table 6. Selection of ram pump features and independent variables to design a pumping system.

\begin{tabular}{ccccc}
\hline No. & Independent variables & Symbol & Value & Dimension \\
\hline 1 & Total input discharge & $Q_{T}$ & 27 & Liter $/ \mathrm{min}$ \\
2 & Length stroke of impulse valve & $S_{0}$ & 0.01 & $\mathrm{~m}$ \\
3 & Disc diameter of impulse valve & $D_{v}$ & 0.03 & $\mathrm{~m}$ \\
4 & Supply head & $H$ & 2.5 & $\mathrm{~m}$ \\
5 & Delivery head & $h$ & 15 & $\mathrm{~m}$ \\
6 & Length of drive pipe & $L$ & 7.01 & $\mathrm{~m}$ \\
7 & Diameter of drive pipe & $D$ & 0.02 & $\mathrm{~m}$ \\
8 & Dead weight of impulse valve & $W$ & 0.13 & $\mathrm{~kg}$ \\
9 & Acceleration due to gravity & $g$ & 9.81 & $\mathrm{~m} / \mathrm{s}^{2}$ \\
10 & Flow density & $\rho$ & 998 & $\mathrm{~kg} / \mathrm{m}^{3}$ \\
\hline
\end{tabular}

Table 7. Steps of designing a pumping system using the ram pump utilized in the present study and the proposed method.

\begin{tabular}{|c|c|c|c|c|}
\hline Step number & Dependent variables & Equation number & Parameter value & Dimension \\
\hline 1 & Drag coefficient $\left(K_{d}\right)$ & (9) & 0.35 & No dimension \\
\hline 2 & Friction coefficient $(c)$ & $(10)$ & 3.06 & No dimension \\
\hline 3 & Flow velocity in steady state $(\nu)$ & - & 4 & $\mathrm{~m} / \mathrm{s}$ \\
\hline 4 & Critical velocity $\left(\nu_{0}\right)$ & $(12)$ & 1.98 & $\mathrm{~m} / \mathrm{s}$ \\
\hline 5 & Maximum delivery head $\left(h_{m}\right)$ & $(11)$ & 25.95 & $\mathrm{~m}$ \\
\hline 6 & Rate of pumping discharge $(q)$ & $(13)$ & 2.22 & Liter/min \\
\hline 7 & Rate of wasting discharge $(Q)$ & $(14)$ & 24.14 & Liter/min \\
\hline 8 & Frequency of impulse valve $(n)$ & $(15)$ & 1.50 & Beat/min \\
\hline 9 & Number of cycles per minute & - & 90 & Beat \\
\hline 10 & Pump efficiency $(\eta)$ & $(16)$ & 22.47 & $\%$ \\
\hline
\end{tabular}

Table 6. Having sufficient variables and information about the pump set and its location, the pumping system of the ram pump was designed and steps of the design process are presented in Table 7.

According to the results in Tables 5 to 7 , under identical geometric and hydrometric conditions, the ram pump used in this study could pump about 3196.8 liters during 24 hours to the height of $15 \mathrm{~m}$. However, the Wilcox ram pump could pump about 2030.4 liters during 24 hours to the same height. In addition, comparison of the performances of the ram pump used in this study and the Wilcox ram pump for various delivery heads is presented in Table 8. Delivery heads were selected between 6 to $20 \mathrm{~m}$ with the step of $2 \mathrm{~m}$.
It is worth noting that the parameter of efficiency in Table 8 was determined using Rankine's efficiency or $\eta_{R}=(q(h-H) / Q H)$, which was used to compare the performances of ram pumps in identical situations. Brief results in Table 8 show that the ram pump designed in the present study could be operated with high efficiency and it could pump more discharge than Wilcox's ram in low delivery heads.

\section{Conclusions}

The results showed that relative pumping discharge $\left(q / Q_{T}\right)$, relative wasting discharge $\left(Q / Q_{T}\right)$, and ram pump efficiency $(\eta)$ were independent from the Reynolds number (Re), Froude number (Fr), Mach 
Table 8. Performance comparison between the ram pump used in this study and the Wilcox's ram pump.

\begin{tabular}{|c|c|c|c|c|c|c|c|c|c|}
\hline \multirow{2}{*}{ No. } & \multirow{2}{*}{$h / H$} & \multicolumn{4}{|c|}{ Wilcox's ram pump } & \multicolumn{4}{|c|}{ Ram pump used in the present study } \\
\hline & & $q / Q_{T}$ & $Q / Q_{T}$ & $n D / \nu_{0}$ & Efficiency & $q / Q_{T}$ & $Q / Q_{T}$ & $n D / \nu_{0}$ & Efficiency \\
\hline 1 & 2.4 & 0.130 & 0.869 & 0.019 & 25.81 & 0.309 & 0.707 & 0.014 & 75.03 \\
\hline 2 & 3.2 & 0.098 & 0.901 & 0.019 & 15.83 & 0.271 & 0.761 & 0.016 & 51.84 \\
\hline 3 & 4 & 0.078 & 0.921 & 0.019 & 11.36 & 0.213 & 0.805 & 0.017 & 35.24 \\
\hline 4 & 4.8 & 0.065 & 0.934 & 0.019 & 8.84 & 0.151 & 0.844 & 0.017 & 22.65 \\
\hline 5 & 5.6 & 0.056 & 0.943 & 0.019 & 7.23 & 0.101 & 0.878 & 0.019 & 14.06 \\
\hline 6 & 6.4 & 0.049 & 0.95 & 0.019 & 6.11 & 0.066 & 0.908 & 0.019 & 8.69 \\
\hline 7 & 7.2 & 0.043 & 0.956 & 0.019 & 5.29 & 0.044 & 0.936 & 0.02 & 5.47 \\
\hline 8 & 8 & 0.039 & 0.960 & 0.019 & 4.67 & 0.029 & 0.962 & 0.021 & 3.53 \\
\hline
\end{tabular}

number (Ma), and friction coefficient of fluid $(f)$. Consequently, dependent parameters were pressure head ratio $\left(h / h_{m}\right)$ and length to diameter ratio of the drive pipe $(L / D)$. However, impulse valve parameter or frequency was a function of Reynolds number, pressure head ratio, and length to diameter ratio of drive pipe. The characteristic curves and the related governing characteristic equations presented in this study could be used for design and performance evaluation of a ram pump system.

\section{Acknowledgments}

The authors would like to thank the Jundi-Shapur University of Technology for the supports that made the experimental program possible. Also, special thanks to Mr. Ali Bandari who made the experimental model in the Hydraulic and River Engineering Laboratory.

\section{References}

1. Filipan, V. and Virag, Z. "Mathematical modeling of a hydraulic ram pump system", Strojniški vestnik Journal of Mechanical Engineering, 49, pp. 137-149 (2003).

2. O'Brien, M.P., and Gosline, J.E. The Hydraulic Ram, University of California press, pp. 20-117 (1933).

3. Krol, J. "The automatic hydraulic ram", Proceedings of the Institution of Mechanical Engineers, 165, pp. 53-73 (1951).

4. Rennie, L. and Bunt, E. "The automatic hydraulic ram", South African Mechanical Engineer, 31, pp. 258273 (1981).

5. Schiller, E., and Kahangire, P. "Analysis and computerized model of the automatic hydraulic ram pump", Canadian Journal of Civil Engineering, 11, pp. 743750 (1984).
6. Basfeld, M., and Müller, E.-A. "The hydraulic ram", Forschung im Ingenieurwesen, 50(5), pp. 141-147 (1984).

7. Tacke, J. "Hydraulic rams; a comparative investigation", TU Delft, Report 88-1 (1988).

8. Rennie, L.C. and Bunt, E.A. "The automatic hydraulic ram-experimental results", Proceedings of the Institution of Mechanical Engineers, Part A: Journal of Power and Energy, 204, pp. 23-31 (1990).

9. Young, B. "Design of hydraulic ram pump systems", Proceedings of the Institution of Mechanical Engineers, Part A: Journal of Power and Energy, 209, pp. 313322 (1995).

10. Young, B. "Simplified analysis and design of the hydraulic ram pump", Proceedings of the Institution of Mechanical Engineers, Part A: Journal of Power and Energy, 210, pp. 295-303 (1996).

11. Young, B. "Design of homologous ram pumps", Journal of Fluids Engineering, 119, pp. 360-365 (1997).

12. Najm, H., Azoury, P., and Piasecki, M. "Hydraulic ram analysis: a new look at an old problem", Proceedings of the Institution of Mechanical Engineers, Part A: Journal of Power and Energy, 213, pp. 127-141 (1999).

13. Maratos, D. "Technical feasibility of wave power for seawater desalination using the hydro-ram (Hydram)", Desalination, 153, pp. 287-293 (2002).

14. Suarda, M. and Wirawan, I. "Kajian eksperimental pengaruh tabung udara pada head tekanan pompa hidram", Jurnal Energi Dan Manufaktur, 3, pp. 7082 (2008).

15. Saito, S., Takahashi, M., and Nagata, Y. "Effects of the air volume in the air chamber on the performance of water hammer pump", International Journal of Fluid Machinery and Systems, 4(2), pp. 225-261 (2011).

16. Nwosu, C.A. and Madueme, T.C. "Recycled micro hydropower generation using hydraulic ram pump (hydram)", International Journal of Research in Engineering \& Technology, 1(3), pp. 1-10 (2013). 
17. Sheikh, S., Handa, C.C. and Ninawe, A.P. "Design methodology for hydraulic ram pump (hydram)", International Journal of Mechanical Engineering and Robotic Research, 2(4), pp. 170-175 (2013).

18. Yang, K., Li, J., Guo, Y., Fu, H., and Wang, T. "Design and hydraulic performance of a Novel hydraulic ram pump", International Conference on Hydro-Informatics: City College of New York, USA, pp. 1-11 (2014).

19. Inthochot, M., Saehaeng, S., Max, J., Muller, J., and Spreee, W. "Hydraulic ram pumps for irrigation in northern Thailand", Proceeding of Agriculture and Agricultural Science, 5, pp. 107-114 (2015).

20. Mbiu, R.N., Maranga, S.M., and Mwai, M. "Performance testing of hydraulic ram pump", Proceedings of the Sustainable Research and Innovation (SRI) Conference, pp. 1-9 (2015).

\section{Biographies}

Reza Fatahi-Alkouhi received the Diploma degree in Civil Engineering from Shahrekord's Conservatory of Fani 1, the BSc degree in Civil Engineering from the Daneshpajoohan Higher Education Institute, and the MSc degree in Civil and River Engineering from JundiShapur University of Technology. Currently, he is PhD candidate in Civil and Water Resource Management at University of Isfahan.

Babak Lashkar-Ara is an Assistant Professor of Civil Engineering at Jundi-Shapur University of Technology. He received his $\mathrm{PhD}$ from Shahid Chamran University, Ahwaz, Iran. His research interests include sediment transport, river engineering, and hydraulic structures. 